\title{
A typical bilateral femoral fracture: A case report
}

\author{
Georgios Gemonas, Panagiotis Lepetsos*, Dimitrios Pallis, Konstantinos Rozis, Dimitrios Georgiou and Michalis Georgoudis \\ Department of Orthopaedic Surgery, KAT Accident's Hospital, Athens, Greece
}

\begin{abstract}
Osteoporosis is a common disease in the elderly, correlated with increased fracture risk, disability and mortality. Bisphosphonates are efficient and have been widely used in the treatment of osteoporosis. Nevertheless, long term bisphosphonate use has been linked with atypical femur fractures. These have a characteristic pattern and history. They usually occur in the proximal third of the femur, and may be complete or incomplete, manifesting either like a radiolucent line or just thickening of the lateral cortex. Their morphology is simple, transverse or short oblique. They are related to minimal, or no trauma at all, but symptoms do pre-exist long before the gross fracture actually takes place.

In this paper we report the case of a 75-year-old woman who sustained an atypical right femur fracture while walking. Her past medical history of osteoporosis treated with alendronate for six years along with symptoms in the contra-lateral thigh for the past 2 years, lead to imaging of the left femur. Thus, our patient had a complete fracture on the right side and an incomplete one, represented by lateral cortex thickening on the left. Treatment consisted of discontinuation of bisphosphonates, intra-medullary nailing of the right femur and conservative treatment of the left side. Uneventful union occurred on both sides.
\end{abstract}

\section{Introduction}

Osteoporosis is a common disease in the elderly, associated with a great fracture risk. That can lead to disability, poor quality of life and mortality. Therapy with most bisphosphonates has shown to reduce the risk of vertebral, non-vertebral and hip fractures in women with postmenopausal osteoporosis and are often considered to be the first choice of treatment [1-4]. Their effectiveness is indicated by reports that demonstrate up to $50 \%$ reduction of vertebral fracture risk and $20-50 \%$ of femoral neck fracture risk $[5,6]$. Bisphosphonates are also indicated in osteoporotic men with great fracture risk. However, many cases of atypical femoral fractures have been described after long-term use of bisphosphonates [7-12]. Dell et al. in 2012, suggested that the risk for atypical femoral fractures is $1,78 / 100.000$ person-years in patients receiving bisphosphonates for 6-8 years [13]. On the other hand, other studies suggest that there is no increase in atypical fractures in bisphosphonate users $[13,14]$. According to the ASBMR Task Force paper in 2010, the most common location of the atypical femoral fractures is the proximal one-third of the femoral shaft, but they can also occur anywhere along the diaphysis of the femur from just distal to the lesser trochanter to just proximal to the supracondylar flare of the distal femoral diaphysis [15]. They are noncomminuted complete fractures with transverse or short oblique orientation or incomplete manifested with a radiolucent line within the lateral cortex and are related with low energy trauma or no trauma at all. Most patients often describe a pain in the groin or thigh several weeks or even months before the fracture. Radiologically, they are often associated with localized periosteal stress reaction of the lateral cortex and generalized thickening of the femoral cortex. Many published case reports of bisphosphonaterelated atypical fractures of the femur present unilateral fractures or bilateral fractures that occurred at different times or both perfect and imperfect contralateral fracture simultaneously, as described in our case. The treatment is surgical with intramedullary nailing and at the same time suspension of the bisphosphonate therapy. Fractures of the femoral head or peritrochanteric region fractures with spiral extension to subtrochanteric region, pathological fractures related to primary or metastatic cancer and periprosthetic fractures must be excluded from this category of atypical fractures [16].

\section{Case report}

A 75-year-old patient was transferred with an ambulance to our hospital because of sharp pain in her right thigh during gait. Clinical examination revealed tenderness, swelling and paradoxical movement in the middle of the right femur. The radiological examination showed a fracture of the right femoral shaft.

Patient's medical history comprises hypertension, carotid stenosis, dyslipidemia, appendectomy, cholecystectomy andhysterectomy. The patient undergoes therapy with alendronate for six years due to osteoporosis. The patient also reports occasional feeling of heaviness in the left thigh over the past 2 years. This information from her medical history combined with the typical morphology of the fracture (noncomminuted transverse fracture of the femoral shaft), led the diagnostic approach to radiological investigation of the left femur too. The radiological examination revealed incomplete atypical fracture of the left femoral shaft with increased thickness of the lateral cortex (Figure 1).

Blood tests results: $\mathrm{Ca}=9.2 \mathrm{mg} / \mathrm{dl} \quad(8.4-10.2), \mathrm{P}=3.9 \mathrm{mg} / \mathrm{dl} \quad(2.5$ 5.0), $\quad \mathrm{ALP}=44 \mathrm{U} / \mathrm{L} \quad(40-150), \quad 25(\mathrm{OH}) \mathrm{D} 3=22.30 \mathrm{ng} / \mathrm{ml} \quad(30-100)$, $\mathrm{iPTH}=69.02 \mathrm{pg} / \mathrm{m} \quad(15-80), \quad \mathrm{NTx}=12.1 \quad(6.2-19), \quad \mathrm{PINP}=42.4 \mathrm{ng} / \mathrm{ml}$ (16.3-73.9) and Ca markers (CEA, CA15-3, CA-125, AFP, CA19-9) are within normal values. The bone density scan that was performed during the days of hospitalization, using DEXA method in the lumbar region and in the left hip, revealed osteopenia. The DEXA showed L2-

${ }^{*}$ Correspondence to: Panagiotis Lepetsos, Nikis 2, Kifisia, Athens 14561, Greece, Tel: +306972184820; E-mail: plepetsos@med.uoa

Key words: bisphosphonates, atypical femoral fracture, osteoporosis treatment Received: May 14, 2018; Accepted: May 29, 2018; Published: June 04, 2018 
L4 BMD of $0.761 \mathrm{~g} / \mathrm{cm}^{2}-$ T-score: $-2.02 \mathrm{SD}$, neck of the left hip BMD of $0.702 \mathrm{~g} / \mathrm{cm}^{2}$ - T-score: -1.9 SD and total hip BMD of $0.779 \mathrm{~g} / \mathrm{cm}^{2}-$ T-score: $-1.9 \mathrm{SD}$. Laboratory results of the patient performed previously presented normal values of ALP, thus excluding hypophosphatasia from differential diagnosis.

According to the newest guidelines of the ASBMR (American Society of Bone and Mineral Research), the patient underwent intramedullary nailing of the right femur and was instructed to discontinue bisphosphonate along with non-weight bearing of the left lower extremity [17-19]. Although a bone scan was conducted for further investigation of the incomplete fracture and the presence of other imperfect fracture sites, no new lesions were found (Figures 2 and 3). After 6 weeks, there was a clinical improvement in the left femur and radiographic appearance of callus, thus excluding the prophylactic intramedullary nailing of the left femur. The union of both fractures developed normally both for the right femur which was treated with intramedullary nailing and the left femur where conservative treatment was selected. The union of the right femur was not affected by the fact that the distal locking screw was not centered in the nail hole. The radiographic monitoring of the bone healing was conducted at 3,6 and 12 months after the first treatment took place (Figures 4 and 5).

\section{Discussion}

The administration of bisphosphonates for the therapy of osteoporosis is effective and well tolerated, but long-term administration has been associated with fractures of the femoral
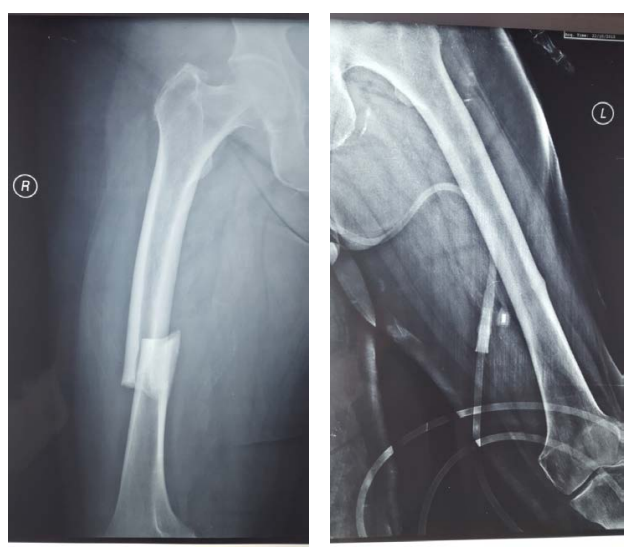

Figure 1. AP radiographs of both femurs. The radiograph of the right femoral shaft shows a complete atypical femoral fracture. The radiograph of the left femoral shaft shows an incomplete atypical femoral fracture with increased thickness of the lateral cortex associated with a radiolucent horizontal line

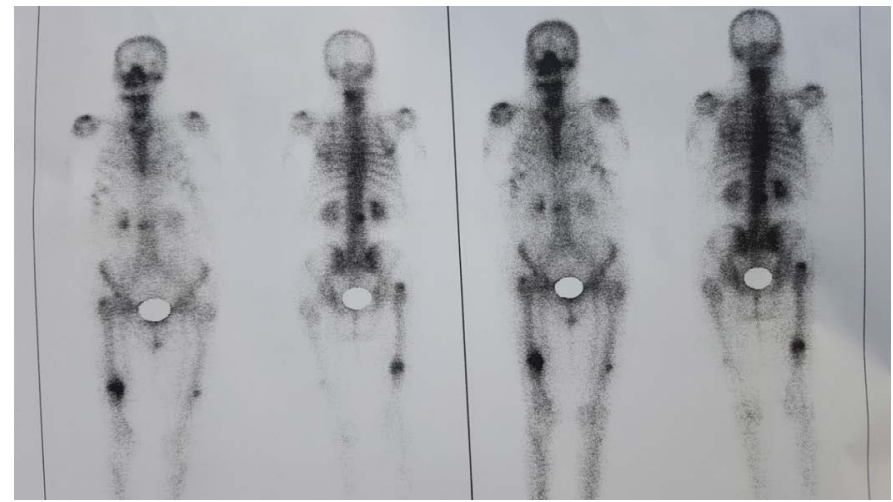

Figure 2. Bone scan

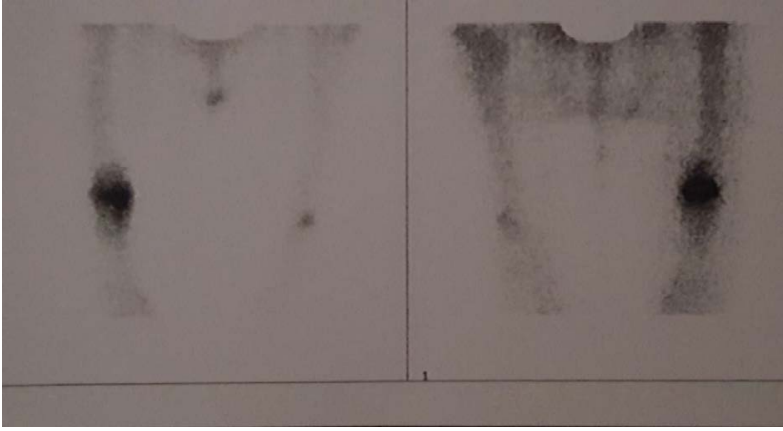

Figure 3. Bone scan

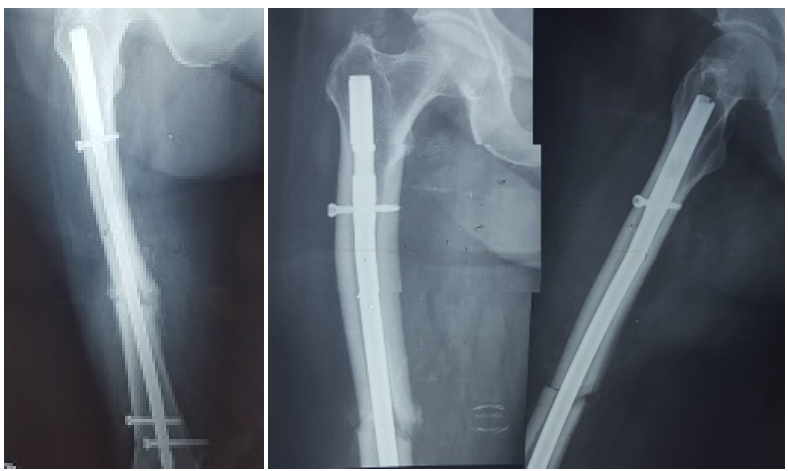

Figure 4. Postoperative radiographs taken two and six months after surgery. The left one shows one AP view of the femoral shaft with the IM nail. The other two shows one AP and $P$ view of the upper one half of the femur

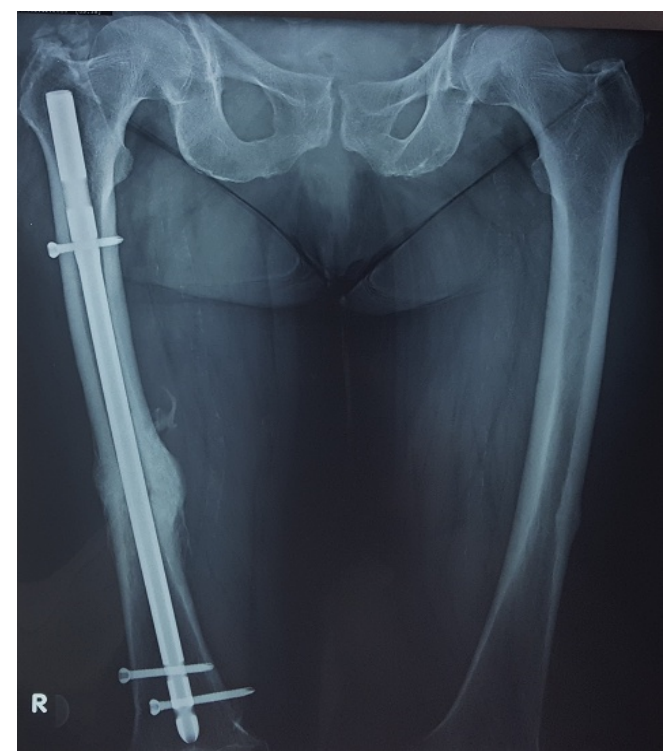

Figure 5. AP radiograph of both femoral shafts 1-year after surgery

shaft and subtrochanteric area. In addition, there is great interest concerning the incidence, etiology and pathophysiology of this kind of fractures. According to the ASBMR Task force, atypical femoral fractures are stress fractures that are unable to heal secondary to the suppression of remodeling due to the bisphosphonate treatment. Also, the primary location in the lateral cortex suggests that reduced tensile strength may be another possible pathogenetic mechanism, propably due to the changes in bone properties as a result of low bone turnover. There are also several other mechanisms proposed for the pathophysiology and etiology of atypical femoral fractures, but their 
correlation with long-term use of bisphosphonates still remains unclear [17]. Reviewing international literature, many cases of atypical femoral fractures have been referred, demonstrating the hazards of long term administration and the necessity for close supervision of this group of patients to detect early symptoms [20-22]. Studies on effectiveness of antiosteoporotic drugs have measured hip fractures in general and not femoral neck fractures or intertrochanteric in particular. A systematic review and meta-analyses of 5 case control studies and 6 cohort studies has suggested that there is a $\mathrm{RR}=1.70$ of subtrochanteric, femoral shaft and atypical fractures of the femur amongst bisphosphonate-treated patients and $R R=11.78$ when studying in particular atypical femoral fractures and bisphosphonate exposure [23]. However, there is still no consensus regarding the pathogenic mechanism that is responsible for causing atypical fractures after the long-term use of bisphosphonates, as suppression of bone remodeling that was previously described is common to all patients taking bisphosphonates and not only to those who suffered the atypical fracture.

The optimal duration of bisphosphonates use is not clear. Because of their high affinity to hydroxyapatite, they remain on bone surfaces for a long period. That is why when osteopenia levels are achieved, their administration should be discontinued for 3-5 years and then resumed again if needed [24]. Teriparatide, a recombinant form of parathyroid hormone(PTH), has shown benefits on treatment of atypical femoral fractures [25-27]. It acts as an anabolic agent by inducing the formation of new bone and by reversing the suppression of bone turnover that is caused by bisphosphonates, which might be a possible mechanism of atypical femoral fractures. The limited data available for the beneficial effect of Teriparatide on fracture healing leads to the necessity for further investigation relative to its use in the treatment of atypical femoral fractures.

Most of the atypical femoral fractures, according to the literature, that are associated with administration of bisphosphonates such as alendronate, differ from common osteoporotic fractures, highenergy fractures and periprosthetic fractures and include: low-energy trauma or no trauma, history of alendronate use for osteoporosis after menopause, onset of spontaneous thigh pain before the fracture, different location than common osteoporotic fractures (spine, hip, wrist), bilateral presentation (sequentially or simultaneously), hypertrophy or increased thickness of the cortex at the radiographs in the fracture site, an uncommon form of fracture (transverse or short oblique) and delayed healing time [28].

Several cases of patients that sustained atypical femoral fractures after long-term administration of bisphosphonatesare reported in international literature $[29,30]$. The majority of fractures occurred after oral administration of alendronate $(>95 \%)$ and the rest after oral administration of risedronate and intravenous administration of pamidronate and zoledronate. In few of these case reports, there was reference in bone turnover markers and in even fewer of them these markers were reduced [24]. In a recent prospective study of 100 asymptomatic patients receiving bisphosphonates for over 3 years, the incidence of incomplete atypical femoral fractures was $2 \%$ [31]. The majority refers to unilateral fractures or sequential bilateral fractures which are reported up to $28 \%$ of the patients, or perfect and imperfect simultaneous contralateral fracture, as happened in our case [31]. There are very few reports for simultaneous perfect bilateral atypical femoral fractures or simultaneous bilateral femoral fractures without prior use of drugs that affect bone metabolism.

The occurrence of atypical fractures after long-term administration of bisphosphonates, strongly differs among patients and possibly the administration of drugs which alter the bone turnover rate can affect some patients more than others. If this point of view is correct, then this characteristic side effect of bisphosphonates and other antiosteoclastic drugs is probably due to genetic differences and not due to anti-osteoclastic drugs [32]. The future solution will be to identify the corresponding genes and take precautions when administering this kind of drugs to people who have those genes [33].

In the case report that we present, the treatment was selected according to the newest guidelines of ASBMR Task Force and involved surgical treatment for the complete fracture and conservative treatment for the incomplete fracture while suspending the administration of bisphosphonates, which is mandatory.

\section{Conclusion}

The rational use of bisphosphonates is crucial to minimize the risk of osteoporotic fractures and atypical femoral fractures. The presentation of this incident demonstrates the importance of close observation of those patients who undergo bisphosphonate treatment, so that we can recognize prodromal symptoms of atypical fractures of the femur and avoid such complications, and the need for personalized treatment according to guidelines in patients with atypical femoral fractures.

\section{Competing interests}

No relevant disclosures

\section{References}

1. Bone HG, Hosking D, Devogelaer JP, Tucci JR, Emkey RD, et al. (2004) Ten years experience with alendronate for osteoporosis in postmenopausal women. $N$ Engl J Med 350: 1189-1199. [Crossref]

2. Eastell R, Barton I, Hannon RA, Chines A, Garnero P, et al. (2003) Relationship of early changes in bone resorption to the reduction in fracture risk with risedronate. $J$ Bone Miner Res 18: 1051-1056. [Crossref]

3. Tonino RP, Meunier PJ, Emkey R, Rodriguez-Portales JA, Menkes CJ, et al. (2000) Skeletal benefits of alendronate: 7-year treatment of postmenopausal osteoporotic women. Phase III Osteoporosis Treatment Study Group. J Clin Endocrinol Metab 85: 3109-3115. [Crossref]

4. Watts NB, Bilezikian JP, Camacho PM, Greenspan SL, Haris ST, et al. (2010) American Association of Clinical Endocrinologists Medical Guidelines for Clinical Practice for the diagnosis and treatment of postmenopausal osteoporosis. Endocr Pract 16:1-37. [Crossref]

5. Nguyen ND, Eisman JA, Nguyen TV (2006) Anti-hip fracture efficacy of biophosphonates: a Bayesian analysis of clinical trials. J Bone Miner Res 21: 340-349. [Crossref]

6. Boonen S, Kay R, Cooper C, Haentjens P, Vanderschueren D, et al. (2009) Osteoporosis management: a perspective based on bisphosphonate data from randomised clinical trials and observational databases. Int J Clin Pract 63: 1792-1804. [Crossref]

7. Capeci CM, Tejwani NC (2009) Bilateral low-energy simultaneous or sequential femoral fractures in patients on long-term alendronate therapy. J Bone Joint Surg Am 91: 2556-2561. [Crossref]

8. Cheung RK, Leung KK, Lee KC, Chow TC (2007) Sequential non-traumatic femora shaft fractures in a patient on long-term alendronate. Hong Kong Med J 13: 485-489. [Crossref]

9. Demiralp B, Ilgan S, Ozgur Karacalioglu A, Cicek EI, Yildrim D, et al. (2007) Bilatera femoral insuffiency fractures treated with inflatable intramedullary nails: A case report. Arch Orthop Trauma Surg 127: 597-601. [Crossref]

10. Goh SK, Yang KY, Koh JS, Wong MK, Chua SY, et al. (2007) Subtrochanteric insufficiency fractures in patients on alendronate therapy: A caution. J Bone Joint Surg $\operatorname{Br}$ 89: 349-353. [Crossref]

11. Isaacs JD, Shidiak L, Harris IA, Szomor ZL (2010) Femoral insufficiency fractures associated with prolonged bisphosphonate therapy. Clin Orthop Relat Res 468: 3384 3392. [Crossref]

12. Lenart BA, Lorich DG, Lane JM (2008) Atypical fractures of the femoral diaphysis in postmenopausal women taking alendronate. $N$ Engl J Med 358: 1304-1306. [Crossref] 
13. Giusti A1, Hamdy NA, Dekkers OM, Ramautar SR, Dijkstra S, et al. (2011) Atypical fractures and bisphosphonate therapy: A cohort study of patients with femoral fracture with radiographic adjudication of fracture site and features. Bone 48: 966-971. [Crossref]

14. Nieves JW, Bilezikian JP, Lane JM, Einhorn TA, Wang Y, et al. (2010) Fragility fractures of the hip and femur: Incidence and patient characteristics. Osteoporos Int 21: 399-408. [Crossref]

15. Shane E, Burr D, Ebeling P, Abrahamsen B, Adler RA, et al. (2010) Atypical subtrochanteric and diaphyseal femoral fractures: report of a task force of the American Society for Bone and Mineral Research. J Bone Miner Res 25: 2267-2294. [Crossref]

16. Zafeiris CP, Stathopoulos IP, Kourkoumelis G, Gkikas E, Lyritis GP (2012) Simultaneous bilateral atypical femoral fractures after alendronate therapy. J Musculoskelet Neuronal Interact 12: 262-264. [Crossref]

17. Shane E, Burr D, Abrahamsen B, Adler RA, Brown TD, et al. (2014) Atypical subtrochanteric and diaphyseal femoral fractures: second report of a task force of the American Society for Bone and Mineral Research. J Bone Miner Res 29: 1-23. [Crossref]

18. Toro G, Ojeda-Thies C, Giampiero Calabrò, Gabriella Toro, Antimo Moretti, et al (2016) Management of atypical femoral fracture: A scoping review and comprehensive algorithm. BMC Musculoskelet Disord 17: 227. [Crossref]

19. Anas Saleh, Hegde VV, Potty AG, Schneider R, Cornell CN, et al. (2012) Management strategy for symptomatic bisphosphonate-associated incomplete atypical femoral fractures. HSS J 8: 103-110. [Crossref]

20. Schilcher J, Michaëlsson K, Aspenberg P (2011) Bisphosphonate use and atypical fractures of the femoral shaft. $N$ Engl J Med 364: 1728-1737. [Crossref]

21. Dell RM, Adams AL, Greene DF, Funahashi TT, Silverman SL, et al. (2012) Incidence of atypical nontraumatic diaphyseal fractures of the femur. J Bone Miner Res 27: 25442550. [Crossref]

22. Thompson RN, Phillips JR, McCauley SH, Elliott JR, Moran CG. (2012) Atypical femoral fractures and bisphosphonates treatment: experience in two large United Kingdom teaching hospitals. J Bone Joint Surg Br 94: 385-390. [Crossref]
23. Gedmintas L, Solomon DH, Kim SC (2013) Bisphosphonates and risk of subtrochanteric, femoral shaft, and atypical femur fracture: a systematic review and meta-analysis. J Bone Miner Res 28: 1729-1737. [Crossref]

24. Bhadada SK, Sridhar S, Muthukrishnan J, Mithal A, Sharma DC, et al. (2014) Predictors of atypical femoral fractures duringlong term bisphosphonates therapy: A case series review of literature. Indian J Med Res 140: 46-54. [Crossref]

25. IM GI, Lee SH (2015) Effect of Teriparatide on Healing of Atypical Femoral Fractures: A Systemic Review. J Bone Metab 22: 183-189. [Crossref]

26. Chiang CY, Zebaze RM, Ghasem-Zadeh A, Iuliano-Burns S, Hardidge A, et al. (2013) Teriparatide improves bone quality and healing of atypical femoral fractures associated with bisphosphonate therapy. Bone 52: 360-365. [Crossref]

27. Tarazona-Santabalbina FJ, Aquilella-Fernadez L (2013) Bisphosphonate long-term treatment related bilateral subtrochanteric femoral fracture. Can teriparatide be useful? Aging Clin Exp Res 25: 605-609. [Crossref]

28. Çakmak S, Mahiroğulları M, Keklikçi K, Sarı E, Erdik B, et al. (2013) Bilateral lowenergy sequential femoral shaft fractures in patients on long-term bisphosphonate therapy. Acta Orthopaedica et Traumatololiga Turcica 47: 162-172. [Crossref]

29. Ovaska MT, Makinen TJ, Madanat R (2011) Simultaneous bilateral subtrochanteric fractures following risedronate therapy. J Orthop Sci 16: 467-470. [Crossref]

30. Gomberg SJ, Wustrack RL, Napoli N, Arnaud CD, Black DM (2011) Teriparatide, vitamin D and calcium healed bilateral subtrochanteric stress fractures in a postmenopausal woman with a 13-year history of continuous alendronate therapy. $J$ Clin Endocrinol Metab 96: 1627-1632. [Crossref]

31. Tarun Pankaj J, Murray T (2012) Atypical femoral fractures related to bisphosphonate therapy. Indian Journal of Radiology and Imaging 22: 178-181. [Crossref]

32. Nicoletti P, Cartsos VM, Palaska PK, Shen Y, Floratos A, et al. (2012) Genomewide pharmacogenetics of bisphosphonate-induced osteonecrosis of the jaw: The role of RBMS3. Oncologist 17: 279-287. [Crossref]

33. LM Havill, MR Allen, JAK Harris, SM Levine, HB Coan, et al. (2013) Intracortica bone remodeling variation shows strong genetic effects. Calcif Tissue Int 93: 472. [Crossref]

Copyright: (C2018 Gemonas G. This is an open-access article distributed under the terms of the Creative Commons Attribution License, which permits unrestricted use, distribution, and reproduction in any medium, provided the original author and source are credited. 